\title{
Comparison of pharmacokinetics of tramadol between young and middle-aged dogs
}

\author{
Takaharu ITAMI ${ }^{1)}$, Yasuo SAITO'), Tomohito ISHIZUKA ${ }^{1)}$, Jun TAMURA ${ }^{1)}$, Mohammed A. UMAR ${ }^{1)}$, Hiroki INOUE ${ }^{2)}$, \\ Kenjiro MIYOSHI ${ }^{1)}$ and Kazuto YAMASHITA ${ }^{1) *}$ \\ ${ }^{1)}$ Department of Small Animal Clinical Sciences, School of Veterinary Medicine, Rakuno Gakuen University, Ebetsu, Hokkaido 069-8501, \\ Japan \\ 2) Department of Biosphere and Environmental Sciences, Faculty of Environment Systems, Rakuno Gakuen University, Ebetsu, Hokkaido \\ 069-8501, Japan
}

(Received 5 November 2015/Accepted 28 January 2016/Published online in J-STAGE 11 February 2016)

\begin{abstract}
This study aimed to compare the pharmacokinetics of tramadol between young and middle-aged dogs. Tramadol (4 mg/kg) was administered intravenously (IV) to young and middle-aged dogs (2 and 8-10 years, respectively). Plasma concentrations of tramadol were measured using high-performance liquid chromatography (HPLC), and its pharmacokinetics best fit a two-compartment model. The volume of distribution $\left(V_{d}\right)$, elimination half-life $\left(t_{1 / 2, \beta}\right)$ and total body clearance $\left(C L_{\text {tot }}\right)$ of the young group were $4.77 \pm 1.07 \mathrm{l} / \mathrm{kg}, 1.91 \pm 0.26 \mathrm{hr}$ and $29.9 \pm 7.3 \mathrm{ml} / \mathrm{min} / \mathrm{kg}$, respectively, while those of the middle-aged group were $4.73 \pm 1.43 \mathrm{l} / \mathrm{kg}, 2.39 \pm 0.97 \mathrm{hr}$ and $23.7 \pm 5.4 \mathrm{ml} / \mathrm{min} /$ $\mathrm{kg}$, respectively. Intergroup differences in the $t_{1 / 2, \beta}$ and $C L_{\text {tot }}$ were significant $(P<0.05)$. In conclusion, tramadol excretion was significantly prolonged in middle-aged dogs.
\end{abstract}

KEY WORDS: dog, intravenous, middle-age, pharmacokinetics, tramadol

doi: 10.1292/jvms.15-0638; J. Vet. Med. Sci. 78(6): 1031-1034, 2016

The physiological changes that accompany advanced aging alter drug distribution and elimination. For instance, morphine clearance has been reported to decrease in elderly human patients [1] who, therefore, require less morphine for pain relief [7]. Tramadol is a centrally acting opioid analgesic widely used in small animal practice to control acute and chronic pain. Tramadol, which is regarded as an effective analgesic, is easily administered, has a longer duration of action and causes fewer adverse effects than most other opioids do [8]. It has been reported that the elimination rate of tramadol is rapid in young beagle [6] and mixed-breed dogs [9] compared with humans [12]. However, the specific relationship between age and pharmacokinetics of tramadol in dogs has not yet been determined. Therefore, the purpose of the present study was to compare the pharmacokinetics of intravenous (IV) tramadol between young and middle-aged dogs.

The Animal Care and Use Committee of Rakuno Gakuen University approved this study (protocol number: H19B21). Two groups of six beagle dogs each consisting of the young (2-year-old, four males and two females, $13.1 \pm 1.0 \mathrm{~kg}$ ) and middle-aged (8-10-years; mean age, $9.7 \pm 0.8$ years; three males and three females; $11.6 \pm 2.6 \mathrm{~kg}$ ) groups were used in this study. The dogs were considered in good health based on physical examinations, complete blood cell count and serum

*Correspondence to: Yamashita, K., Department of Small Animal Clinical Sciences, School of Veterinary Medicine, Rakuno Gakuen University, Ebetsu, Hokkaido 069-8501, Japan.

e-mail: yamasita@rakuno.ac.jp

(C)2016 The Japanese Society of Veterinary Science

This is an open-access article distributed under the terms of the Creative Commons Attribution Non-Commercial No Derivatives (by-nc-nd) License $<$ http://creativecommons.org/licenses/by-nc-nd/4.0/>. biochemical analyses. The dogs were fasted for $12 \mathrm{hr}$ before each experiment.

Then, the dogs received an IV bolus injection of tramadol (Tramal, Nippon Shinyaku, Kyoto, Japan) at a dose of 4 $\mathrm{mg} / \mathrm{kg}$ through a 22-gauge catheter (Happycath Z, Medikit, Tokyo, Japan) inserted into the left cephalic vein. Blood samples $(2 \mathrm{~m} l)$ were collected through the 18-gauge central vein catheter (Indwelling vascular catheter kit, Medikit) inserted into the left jugular vein and mixed with heparin sodium (30 units per $1 \mathrm{ml}$ of blood) at 2, 5, 10, 15, 20, 30 and $45 \mathrm{~min}$ and $1,1.5,2,3,4,5,6,12,24,48$ and $72 \mathrm{hr}$ after tramadol administration. These blood samples were immediately centrifuged $(1,500 \times g$ for $10 \mathrm{~min})$ to separate the plasma and deproteinized as previously reported [5]; then, the upper layer was extracted and stored at $-80^{\circ} \mathrm{C}$ until highperformance liquid chromatography (HPLC) analysis.

To construct the calibration curve, serial dilutions of the extracts were prepared (final tramadol concentrations, 2.5$1,000 \mathrm{ng} / \mathrm{m} l$ ) by fortifying the pooled canine plasma with tramadol and stored in the same deep freezer. The coefficient of variation was determined using six replicates each at 50 , 250, 500 and 1,000 $\mathrm{ng} / \mathrm{ml}$. Calibration was performed each day and only used, if the coefficient of determination $\left(r^{2}\right)$ was greater than 0.99 with all values within $15 \%$ of the expected true concentration. The maximum value of the coefficient of variation in the intra and inter precision assays and mean recovery for tramadol were 8.5 and $95.4 \%$, respectively.

The HPLC system consisted of a dual pump (DP-8020, Toso, Tokyo, Japan), reversed-phase column (Unison UKC18, Toso), degasser (AG-12, Toso) and an intelligent fluorescence detector (FS-8020, Toso). The tramadol in each extract sample was separated using a reverse-phase column with a linear gradient mobile phase of methanol:water:ammonium acetate $(24: 75.94: 0.06)$ to $100 \%$ methanol. The flow rate was 
$0.3 \mathrm{ml} / \mathrm{min}$, and the fluorescence detector was set at 270 and $304 \mathrm{~nm}$ (excitation and emission, respectively). The retention time for tramadol was $7 \mathrm{~min}$, and its concentration in the samples was estimated using the calibration curve.

The pharmacokinetic parameters of tramadol were calculated using the LC-8020 software (Toso). The curve fitting was performed using an interactive least-squares approach, using the MULTI computer program (free software based on Microsoft Excel provided by the Graduate School of Pharmaceutical Sciences, Faculty of Pharmaceutical Sciences, Kyoto University, Kyoto, Japan) [14]. A weighting factor $\left(1 / y^{2}\right)$ was applied to the pharmacokinetic calculations. The best-fitting model for the compartmental analysis was determined using residual plots and Akaike's Information Criterion. The compartmental pharmacokinetic parameters including the total body clearance $\left(C L_{\text {tot }}\right)$, volume of distribution at steady-state $\left(V_{\mathrm{dss}}\right)$, area under the curve $(A U C)$ and mean residence time $(M R T)$ were calculated using equations published previously [2].

The data are expressed as means \pm standard deviation (SD) or median [range]. The pharmacokinetic parameters were determined using the normality test and $F$-test, and then, between-group comparisons were performed using an unpaired Student's $t$-test or Mann-Whitney $U$-test using computer software (Statcel3, OMS Publishing, Saitama, Japan). A $P<0.05$ was considered significant.

No nausea and vomiting were observed after IV administration of tramadol at $4 \mathrm{mg} / \mathrm{kg}$ in either group, and none of the dogs appeared sedate after the treatment. All the animals ate, drank, defecated and urinated normally throughout the experimental period. On the other hand, it has been reported that side effects, such as nausea, salivation and tremor, were induced by intravenous administration of tramadol at similar doses to those used in our study in dogs [9]. To obtain analgesia without side effects, it is important in clinical situations to adjust the effective blood concentration of tramadol.

In the present study, the limit of tramadol quantification for the HPLC analysis was determined to be $10 \mathrm{ng} / \mathrm{m} l$ based on the calibration curve. Since plasma samples were diluted 16.8-fold during preparation, the minimum concentration of tramadol detectable in this study was $168 \mathrm{ng} / \mathrm{ml}$.

Changes in the plasma concentrations of tramadol are shown in Fig. 1. The pharmacokinetics of tramadol were best fitted to a two-compartment model in both groups. The plasma concentrations of tramadol decreased to levels below the limit of quantification in all dogs in the young group $4 \mathrm{hr}$ after drug administration. On the other hand, tramadol was detected in plasma samples from all the middle-aged group dogs for up to $12 \mathrm{hr}$ after administration. The plasma tramadol concentrations were highest (1,500 and 2,250 $\mathrm{ng} / \mathrm{ml}$, young and middle-aged groups, respectively) approximately 2 min after IV injection, rapidly decreased during the first 20 min and then decreased more slowly.

Pharmacokinetic evaluations were carried out for tramadol, and the corresponding parameters are summarized in Table 1. There was no significant difference in the $V_{\mathrm{dss}}$ of tramadol between the groups. The $C L_{\text {tot }}$ was significantly lower in the middle-aged group than it was in the young

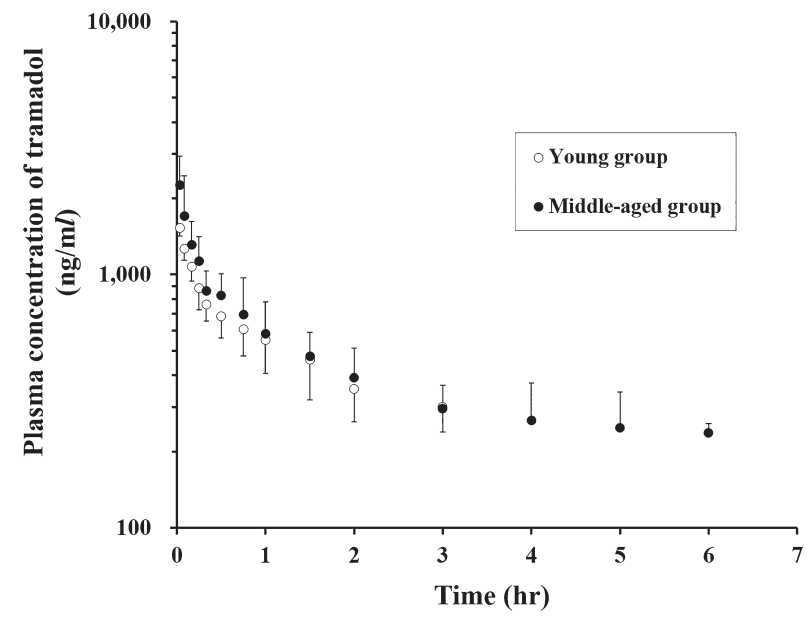

Fig.1. Plasma concentration versus time curves for tramadol following intravenous injection of tramadol $(4 \mathrm{mg} / \mathrm{kg})$ to young and middle-aged dogs (2-and 8-10-year-old, respectively). Data are mean \pm standard deviation (SD) of plasma concentration for young $(\circ)$ and middle-aged groups $(\bullet)(n=6$ each). Limit of detection for tramadol was $168 \mathrm{ng} / \mathrm{ml}$. Plasma concentrations of tramadol were below limit of detection at 4 and $12 \mathrm{hr}$ in young and middle-aged dogs, respectively, after administration.

group $(P<0.05)$. The $t_{1 / 2 \beta}$ and $A U C$ were significantly higher in the middle-aged group than they were in the young group $\left(P<0.05\right.$ each). Therefore, the differences in $C L_{\text {tot }}$ and $t_{1 / 2 \beta}$ might be related to the differences in the limit of quantification between young and middle-aged dogs at $4 \mathrm{hr}$ or later.

The pharmacokinetic profiles of tramadol were previously reported in young beagle dogs of an unspecified age [6] and mixed-breed dogs aged 3-5 years [9]. There were small differences in the $\mathrm{V}_{\mathrm{d}}, C L_{\text {tot }}$ and $t_{1 / 2 \beta}$ of tramadol reported in young dogs between the present study $(4.77 \pm 1.97 \mathrm{l} / \mathrm{kg}, 29.5$ $\pm 7.3 \mathrm{ml} / \mathrm{min} / \mathrm{kg}$ and $1.91 \pm 0.26 \mathrm{hr}$, respectively) and the previous reports $(3.42 \pm 0.47 \mathrm{l} / \mathrm{kg}, 35.58 \pm 2.96 \mathrm{ml} / \mathrm{min} / \mathrm{kg}$ and $1.36 \pm 0.36 \mathrm{hr}$, respectively) using the same IV dose of tramadol [9]. This might be attributable to differences in the analytical methods used to determine the plasma tramadol concentration and the population of the study dogs. Our data agreed with previous reports that plasma tramadol concentrations were best fitted to a two-compartment model $[6,9]$.

Tramadol is metabolized in the liver, and its metabolites are primarily excreted via the kidney $(90 \%)$ with the remaining $(10 \%)$ being excreted in the feces [15]. Drug elimination may be altered by decreased liver metabolism, reduced renal excretion, and reduced hepatic and renal blood flow, resulting in slower delivery of drugs to the liver [10]. Particular caution should be exercised when extended administration intervals are used in dogs with liver and kidney malfunctions [11]. In the present study, although the general physical conditions and biochemical analysis were normal, the $C L_{\text {tot }}$ was decreased and $t_{1 / 2 \beta}$ was prolonged in middle-aged dogs compared with young dogs. Therefore, it was considered that the administration interval or infusion rate of tramadol was extended in middle-aged dogs. 
Table 1. Pharmacokinetic parameters of tramadol after intravenous administration in young dogs and middleaged dogs (2 and 8-10-year-old, respectively)

\begin{tabular}{llccc}
\hline Parameters & (units) & Young dogs $(\mathrm{n}=6)$ & Middle-aged dogs $(\mathrm{n}=6)$ & $P$ value \\
\hline $\mathrm{A}$ & $(\mathrm{ng} / \mathrm{m} l)$ & $953.1 \pm 292.4$ & $1,702.3 \pm 439.6$ & 0.003 \\
$\alpha$ & $(/ \mathrm{hr})$ & $7.17 \pm 3.12$ & $6.17 \pm 2.47$ & 0.276 \\
$\mathrm{~B}$ & $(\mathrm{ng} / \mathrm{m} l)$ & $761.6 \pm 211.2$ & $746.8 \pm 291.3$ & 0.461 \\
$\beta$ & $(/ \mathrm{hr})$ & $0.36 \pm 0.05$ & $0.29 \pm 0.12$ & 0.101 \\
$\left.t_{l / 2 \alpha} a^{\mathrm{a}}\right)$ & $(\mathrm{hr})$ & $0.10 \pm 0.05$ & $0.11 \pm 0.05$ & 0.664 \\
$\left.t_{l / 2 \beta}{ }^{\mathrm{a}}\right)$ & $(\mathrm{hr})$ & $1.91 \pm 0.26$ & $2.39 \pm 0.97$ & 0.044 \\
$\mathrm{~K} 12$ & $(/ \mathrm{hr})$ & $3.32 \pm 1.84$ & $3.44 \pm 1.34$ & 0.553 \\
$\mathrm{~K} 21$ & $(/ \mathrm{hr})$ & $3.43 \pm 1.48$ & $2.16 \pm 1.25$ & 0.070 \\
$\mathrm{Kel}$ & $(/ \mathrm{hr})$ & $0.78 \pm 0.17$ & $0.85 \pm 0.26$ & 0.295 \\
$\mathrm{~V} 1$ & $(l / \mathrm{kg})$ & $2.30[1.97-3.31]$ & $1.67[1.26-2.46]$ & $0.055^{\mathrm{b})}$ \\
$\mathrm{V} 2$ & $(l / \mathrm{kg})$ & $2.37 \pm 1.08$ & $3.00 \pm 1.10$ & 0.343 \\
$V d_{s s}$ & $(l / \mathrm{kg})$ & $4.77 \pm 1.07$ & $4.73 \pm 1.43$ & 0.954 \\
$\left.C L_{t o t}{ }^{a}\right)$ & $\left(\mathrm{m} l \cdot \mathrm{min}{ }^{-1} \cdot \mathrm{kg}^{-1}\right)$ & $29.9 \pm 7.3$ & $23.7 \pm 5.4$ & 0.035 \\
$\mathrm{AUC}$ & $(\mathrm{g} \cdot \mathrm{hr} / \mathrm{m} l)$ & $2,257.7 \pm 547.9$ & $3,006.6 \pm 814.2$ & 0.046 \\
$\mathrm{MRT}$ & $(\mathrm{hr})$ & $2.65 \pm 0.31$ & $3.33 \pm 1.36$ & 0.064 \\
\hline
\end{tabular}

Data are mean \pm standard deviation (SD) or median [range]. A, intercept for the distribution phase; $\alpha$, distribution slope; $\mathrm{B}$, intercept for the elimination phase; $\beta$, elimination slope; $t 1 / 2 \alpha$, distribution half-life; $t 1 / 2 \beta$, elimination halflife; K12, K21 and Kel, rate constants; V1, apparent volume of central compartment; V2, apparent volume of the peripheral compartment; $V d s s$, apparent volume of distribution at steady-state; $C L t o t$, total body clearance; $\mathrm{AUC}_{0-\infty}$, area under the curve 0 -infinity; MRT, mean residence time. Pharmacokinetic parameters were compared between groups using unpaired Student's $t$-test or Mann-Whitney $U$-test; a) harmonic mean \pm jackknife SD, b) Mann-Whitney $U$-test.

Unfortunately, the fecal excretion was not quantified, because complete urinary and fecal collections were not performed in the present study. The capacity to biotransform tramadol might decrease with age, because metabolic enzyme activity decreases as well [11]. In addition, one of tramadol's active metabolites, $O$-desmethyltramadol (M1), has a more agonistic effect on the $\mu$-opioid receptor than tramadol does [4]. However, the capacity of beagle dogs to biotransform tramadol to M1 is reportedly very low [3]. In addition, considerably lower M1 plasma concentrations were detected in mixed-breed dogs administered intravenous tramadol at $4.0 \mathrm{mg} / \mathrm{kg}$ [9]. It was also reported that there is a low correlation between plasma concentrations of M1 and the sparing effect on sevoflurane minimum alveolar concentration (MAC) in dogs receiving CRI of tramadol [13]. In addition to the fact that low concentrations of M1 have been reported to correlate with the lack of pain therapy efficacy in dogs [3], it can be concluded that tramadol itself is likely to be responsible for the analgesic effect observed in dogs.

The plasma concentration of tramadol after intermittent injections could be simulated using our pharmacokinetic parameters; therefore, the age-related pharmacokinetic changes observed in this study could be clinically useful for determining dosage regimens. We previously reported that tramadol administration significantly reduced sevoflurane minimum alveolar concentration (MAC) by $22 \%$ in dogs and the plasma concentration of tramadol was approximately $400 \mathrm{ng} / \mathrm{ml}$ at the time of MAC determination [5]. The steady state was attained at $4 \times t_{1 / 2}$, and when the steady-state trough level was $400 \mathrm{ng} / \mathrm{m} l$, the intermittent injection was predicted to be required at intervals of 3 and $3.5 \mathrm{hr}$ in the young and middle-aged groups, respectively (Supplementary Fig. 1). In addition, anesthetic and analgesic agents are often clinically administered using constant-rate infusion (CRI) to obtain a stable plasma concentration. The dosage of tramadol required to achieve a target plasma concentration of $400 \mathrm{ng} /$ $\mathrm{m} l$ based on our pharmacokinetic parameters was predicted to be an IV loading dose (LD) of $1.9 \mathrm{mg} / \mathrm{kg}$ followed by 0.72 $\mathrm{mg} / \mathrm{kg} / \mathrm{hr}$ CRI in the young group. Additionally, to prevent an increase in the plasma concentration of tramadol, the CRI dosage should be reduced in the middle-aged group. To obtain the same plasma concentration, the required dosage of tramadol was predicted to be $1.9 \mathrm{mg} / \mathrm{kg}$ IV (LD) followed by $0.57 \mathrm{mg} / \mathrm{kg} / \mathrm{hr}$ CRI in the middle-aged group. By administering the drug at these infusion rates, a steady state was predicted to occur $30 \mathrm{~min}$ after the injection of tramadol in both groups (Supplementary Fig. 2). Therefore, although the differences in the pharmacokinetic parameters between young and middle-aged dogs were slight, the associated side effects might develop because of drug accumulation with multiple doses or prolonged infusion in middle-aged dogs. Therefore, it might be clinically useful to evaluate the pharmacokinetic parameter of young and middle-aged dogs, to determine the appropriate administration intervals and infusion rates.

Further pharmacokinetics and pharmacodynamics studies are necessary to confirm the optimum doses for intermittent administration and the infusion rate of tramadol in elderly dogs.

In conclusion, the distribution of tramadol was not affected by aging in dogs. However, the excretion of tramadol was significantly prolonged in the middle-aged compared to the young dogs. To achieve the same steady-state trough levels in young dogs, the interval intermittent injections and infusion rates should be extended in middle-aged dogs. 


\section{REFERENCES}

1. Baillie, S. P., Bateman, D. N., Coates, P. E. and Woodhouse, K. W. 1989. Age and the pharmacokinetics of morphine. Age Ageing 18: 258-262. [Medline] [CrossRef]

2. Gibaldi, M. and Perrier, D. 1982. Pharmacokinetics, 2nd ed., Marcel Dekker Inc., New York.

3. Giorgi, M., Del Carlo, S., Saccomanni, G., ŁebkowskaWieruszewska, B. and Kowalski, C. J. 2009. Pharmacokinetics of tramadol and its major metabolites following rectal and intravenous administration in dogs. N. Z. Vet. J. 57: 146-152. [Medline] [CrossRef]

4. Ide, S., Minami, M., Ishihara, K., Uhl, G. R., Sora, I. and Ikeda, K. 2006. Mu opioid receptor-dependent and independent components in effects of tramadol. Neuropharmacology 51: 651-658. [Medline] [CrossRef]

5. Itami, T., Kawase, K., Tamaru, N., Ishizuka, T., Tamura, J., Miyoshi, K., Umar, M. A., Inoue, H. and Yamashita, K. 2013. Effects of a single bolus intravenous dose of tramadol on minimum alveolar concentration (MAC) of sevoflurane in dogs. $J$. Vet. Med. Sci. 75: 613-618. [Medline] [CrossRef]

6. KuKanich, B. and Papich, M. G. 2004. Pharmacokinetics of tramadol and the metabolite O-desmethyltramadol in dogs. J. Vet. Pharmacol. Ther. 27: 239-246. [Medline] [CrossRef]

7. Macintyre, P. E. and Jarvis, D. A. 1996. Age is the best predictor of postoperative morphine requirements. Pain 64: 357-364. [Medline] [CrossRef]

8. Mastrocinque, S. and Fantoni, D. T. 2003. A comparison of preoperative tramadol and morphine for the control of early postoperative pain in canine ovariohysterectomy. Vet. Anaesth. Analg. 30: 220-228. [Medline] [CrossRef]

9. McMillan, C. J., Livingston, A., Clark, C. R., Dowling, P. M., Taylor, S. M., Duke, T. and Terlinden, R. 2008. Pharmacokinetics of intravenous tramadol in dogs. Can. J. Vet. Res. 72 325-331. [Medline]

10. Meyer, R. E. 1999. Geriatric patients. pp. 253-256. In: BSAVA Manual of Small Animal Anaesthesia and Analgesia, 1st ed. (Seymour, C. and Gleed, R. eds.), BSAVA, Cheltenham.

11. Pettifer, G. R. and Grubb, T. L. 2007. Neonatal and Geriatric Patients. pp. 985-991. In: Lumb and Jones' Veterinary Anesthesia and Analgesia, 4th ed. (Tranquilli, W. J., Thurmon, J. C. and Grimm, K. A. eds.), Blackwell Publishing, Ames.

12. Scott, L. J. and Perry, C. M. 2000. Tramadol: a review of its use in perioperative pain. Drugs 60: 139-176. [Medline] [CrossRef]

13. Seddighi, M. R., Egger, C. M., Rohrbach, B. W., Cox, S. K. and Doherty, T. J. 2009. Effects of tramadol on the minimum alveolar concentration of sevoflurane in dogs. Vet. Anaesth. Analg. 36: 334-340. [Medline] [CrossRef]

14. Yamaoka, K., Nakagawa, T. and Uno, T. 1978. Statistical moments in pharmacokinetics. J. Pharmacokinet. Biopharm. 6: 547-558. [Medline] [CrossRef]

15. Wu, W. N., McKown, L. A., Gauthier, A. D., Jones, W. J. and Raffa, R. B. 2001. Metabolism of the analgesic drug, tramadol hydrochloride, in rat and dog. Xenobiotica 31: 423-441. [Medline] [CrossRef] 